\title{
BMJ Open Influence of lifestyle risk factors on work ability and sick leave in a general working population in Norway: a 5-year longitudinal study
}

Marit Müller De Bortoli (D) , ${ }^{1,2}$ Inger M. Oellingrath, ${ }^{1}$ Anne Kristin Moeller Fell (D) , ${ }^{2}$ Alex Burdorf (D) , ${ }^{3}$ Suzan J. W. Robroek ${ }^{3}$

To cite: De Bortoli MM, Oellingrath IM, Fell AKM, et al. Influence of lifestyle risk factors on work ability and sick leave in a general working population in Norway: a 5 -year longitudinal study. BMJ Open 2021;11:e045678. doi:10.1136/ bmjopen-2020-045678

- Prepublication history and additional materials for this paper is available online. To view these files, please visit the journal online (http://dx.doi. org/10.1136/bmjopen-2020045678).

Received 08 October 2020 Revised 03 December 2020 Accepted 19 January 2021

Check for updates

(C) Author(s) (or their employer(s)) 2021. Re-use permitted under CC BY-NC. No commercial re-use. See rights and permissions. Published by BMJ.

${ }^{1}$ Department of Nursing and Health Sciences, University of South-Eastern Norway Campus Porsgrunn, Porsgrunn, Norway

${ }^{2} 0$ ccupational and

Environmental Medicine,

Sykehuset Telemark HF, Skien, Norway

${ }^{3}$ Department of Public Health, Erasmus MC, Rotterdam, ZuidHolland, The Netherlands

Correspondence to Marit Müller De Bortoli; marit.muller@usn.no

\section{ABSTRACT}

Objectives The aim of this study is to assess (1) whether lifestyle risk factors are related to work ability and sick leave in a general working population over time, and (2) these associations within specific disease groups (ie, respiratory diseases, cardiovascular disease and diabetes, and mental illness).

Setting Telemark county, in the south-eastern part of Norway.

Design Longitudinal study with 5 years follow-up. Participants The Telemark study is a longitudinal study of the general working population in Telemark county, Norway, aged 16 to 50 years at baseline in $2013(n=7952)$ and after 5-year follow-up.

Outcome measure Self-reported information on work ability (moderate and poor) and sick leave (short-term and long-term) was assessed at baseline, and during a 5-year follow-up.

Results Obesity (OR=1.64, 95\% Cl: 1.32 to 2.05$)$ and smoking ( $\mathrm{OR}=1.62,95 \% \mathrm{Cl}: 1.35$ to 1.96$)$ were associated with long-term sick leave and, less strongly, with shortterm sick leave. An unhealthy diet $(\mathrm{OR}=1.57,95 \% \mathrm{Cl}: 1.01$ to 2.43$)$, and smoking ( $\mathrm{OR}=1.67,95 \% \mathrm{Cl}: 1.24$ to 2.25$)$ were associated with poor work ability and, to a smaller extent, with moderate work ability. A higher lifestyle risk score was associated with both sick leave and reduced work ability. Only few associations were found between unhealthy lifestyle factors and sick leave or reduced work ability within disease groups.

Conclusion Lifestyle risk factors were associated with sick leave and reduced work ability. To evaluate these associations further, studies assessing the effect of lifestyle interventions on sick leave and work ability are needed.

\section{BACKGROUND}

As in most European countries, the old-age dependency ratio is expected to increase in Norway. It is projected that by 2030 every person of working age will have to support almost 0.4 persons aged over 65 years. ${ }^{1}$ The Norwegian authorities are therefore seeking to increase the duration of participation in paid employment. ${ }^{2}$ The Norwegian welfare
Strengths and limitations of this study

- The study included 6267 subjects from the general working population in Telemark, Norway, with information on work ability and sick leave at baseline and 5-year follow-up.

- Inclusion of several lifestyle-related factors (diet, physical activity, body mass index and smoking) allowed to explore the association between both the exposure to a single lifestyle risk factor as well as to multiple lifestyle risk factors and work ability and sick leave.

- The study reflects the general working population, and thus included participants both from a broad spectre of adults with different sociodemographic backgrounds.

- The study relies on self-reports which can introduce information bias in the study.

state is known for its generous insurance coverage. At the same time, Norway has a high level of sick leave compared with other northern European countries (2.4\% of gross domestic product allocated to sick leave). ${ }^{3}$ Low work ability, defined as the degree to which a worker is physically and mentally able to cope with the demands at work, ${ }^{4}$ has also been related to long-term sickness absence and disability benefits. ${ }^{5}$ Unhealthy lifestyle behaviours are potentially modifiable risk factors. Hence, promoting a healthy lifestyle among workers may enhance work ability and the potential to stay in work, and thereby promote longer work participation. ${ }^{6}$

Several longitudinal studies have explored the association between lifestyle-related risk factors and sick leave. Concerning sick leave, there is convincing evidence of an association between high body mass index (BMI) and sick leave. ${ }^{78}$ Further, prospective studies have indicated an association between low physical activity and sick leave $\mathrm{e}^{9-11}$ and between 
smoking and sick leave. ${ }^{12-14}$ Few longitudinal studies have assessed the association between lifestyle risk factors and work ability. The available studies have shown associations between high BMI and low work ability. ${ }^{15-17}$ Moreover, a systematic review of six longitudinal studies (all Finnish) found that overweight, obesity, physical activity and smoking were associated with low work ability in a wide range of occupational groups. ${ }^{6}$ Lastly, a systematic evaluation of interventions aimed at improving physical activity among workers reported increased work ability compared with control groups. ${ }^{18}$

Despite evidence that lifestyle risk factors tend to cluster, ${ }^{1920}$ only a limited number of studies have explored the association between exposure to several lifestyle risk factors and sick leave and work ability in a general working population. We have previously reported on an association between multiple lifestyle risk factors and low work ability in a cross-sectional study. ${ }^{21}$ Moreover, few studies have explored the relationship between lifestyle risk factors and work ability or sick leave within specific chronic disease groups. ${ }^{22}{ }^{23}$ Non-communicable disease such as mental illness, respiratory diseases and cardiovascular diseases are among the leading causes of sickness absence in Norway. ${ }^{24}$ Insight into the associations between an unhealthy lifestyle, sick leave and reduced work ability both within the general population and within specific common chronic disease groups is needed in order to design effective interventions to increase work ability and reduce sick leave.

The aim of this longitudinal study is (1) to assess whether lifestyle risk factors are related to work ability and sick leave in a general working population over time, and (2) to study these associations within specific disease groups (ie, respiratory diseases, cardiovascular disease and diabetes, and mental illness).

\section{METHODS}

\section{Study design and population}

The study is based on data from the longitudinal, general population based, Telemark study conducted in southeastern Norway in 2013 (baseline). A random sample of 50000 residents aged 16 to 50 years in Telemark received a postal questionnaire in 2013 (baseline). In total, 16099 persons responded (33\% response), and $7952(49 \%)$ also completed the questionnaire at 5-year follow-up (2018). Of these, 7510 respondents answered the questions regarding sick leave and work ability score (WAS) and were included in the study. Persons who were not engaged in paid work at baseline or follow-up were excluded. This resulted in a study sample of 6267 subjects.

\section{Dependent variables}

Sick leave: Sick leave was defined at baseline and follow-up as one or more days of sick leave in the previous 12 months ('Have you been on sick leave during the past 12 months?'). A follow-up question was also asked: 'If yes, for how many days?' (1-7 days, 8-14 days, 15 days-12 weeks, more than 12 weeks). A dichotomous variable was constructed to assess the presence of sick leave (at least 1 day of sick leave in the past 12 months vs no sick leave). Finally, the duration of sick leave was categorised as 'none' (0 days), 'short-term' (1-14 days) and 'long-term' ( $\geq 15$ days).

Work ability: The first item of the work ability index, the work ability score,${ }^{25}$ was used to assess self-rated current work ability at baseline and follow-up. The participants answered the question: 'How do you rate your current work ability compared with your lifetime best', where a score of 0 represents complete work disability and a score of 10 represents work ability at its best. ${ }^{25}$ First, the outcome was dichotomised, defining a WAS of 7 or lower as low work ability and a WAS of 8 or higher as good work ability. ${ }^{25}$ Second, the level of work ability was categorised as 'poor' (WAS 0-5), 'moderate' (WAS 6-7) or 'good' (WAS 8-10). ${ }^{26}$

\section{Independent variables}

Lifestyle risk factors

Self-reported information on lifestyle risk factors was collected at baseline.

\section{Diet}

Dietary information was collected using validated food frequency questions previously used in the Norwegian population-based Nord-Trøndelag Health Study (HUNT3) (2006-2008). ${ }^{27} 28$ To reflect adherence to general dietary advice, a dietary sum score was calculated for each participant based on the recommended intake of fruit and vegetables, fat fish, sausages/hamburgers and chocolate/candies. ${ }^{21}$ The total score for each participant (scale $0-4$ ) was calculated by summarising their scores on the four indicators, reflecting the number of dietary recommendations met. ${ }^{29}$ The responses were coded 0 (not meeting the recommendations) and 1 (meeting the recommendations). The diet score was further divided into three categories: 'unhealthy diet' $(0-1)$, 'average diet' (2) and 'healthy diet' (3-4).

\section{Physical activity}

Moderate to vigorous leisure-time physical activity (MVPA) was determined using questions and cut-off points covering frequency, intensity and duration of exercise, previously validated and used in the HUNT1 (1984$1986)$ and HUNT3 (2006-2008) studies. $^{30}$ To reflect recommendations on adult MVPA $(\geq 150 \mathrm{~min} /$ week $),{ }^{31}$ the responses regarding frequency, intensity and duration were combined into a total MVPA score, according to which 'low MVPA' was defined as less than $60 \mathrm{~min}$ per week, 'moderate MVPA' as between $60 \mathrm{~min}$ and $150 \mathrm{~min}$ per week and 'high MVPA' as 150 min or more weekly.

\section{Body mass index}

Body mass index was calculated based on self-reported height and weight and divided into BMI categories in accordance with the WHO's cut-offs for adults: ${ }^{32}$ "underweight' $\left(<18.5 \mathrm{~kg} / \mathrm{m}^{2}\right)$, 'normal weight' $(18.5-24.9 \mathrm{~kg} /$ 
$\mathrm{m}^{2}$ ), 'overweight' $\left(25-29.9 \mathrm{~kg} / \mathrm{m}^{2}\right)$ and 'obese' ( $\geq 30 \mathrm{~kg} /$ $\left.\mathrm{m}^{2}\right)$. Due to the low prevalence of underweight persons $(1 \%)$, these participants were combined with the participants in the normal weight group.

\section{Smoking}

Smoking habits were divided into three categories, denoted 'current smoker' (every day and occasional smoking combined), 'former smoker' and 'never smoked'.

\section{Lifestyle risk index}

An overall lifestyle risk index was constructed combining multiple lifestyle risk factors (including BMI). The individual lifestyle factors were given weighted risk scores: 0 (low health risk; healthy diet, $\geq 150 \mathrm{~min} /$ week physical activity, normal weight and never smoked), 0.5 (intermediate health risk; average diet, overweight, between 60 and 150 min physical activity per week and former smoker) and 1 (high health risk; unhealthy diet, $<1$ hour/weekly physical activity, obesity and current smoker). The sum of these scores provided a total index ranging from 0 to 4 . This lifestyle risk index was divided into four categories: 'low risk score' (total score 0-0.5), 'medium risk score' (total score 1-1.5), 'high risk score' (total score 2-2.5) and 'very high risk score' (total score 3-4).

\section{Disease groups}

Information on specific diseases was collected by selfreporting at baseline.

\section{Respiratory disease}

Participants were defined as having respiratory disease if they responded affirmatively to any of the following questions: 'Has a physician ever diagnosed you with asthma?'; 'Has a physician told you that you have chronic obstructive pulmonary disease?'; 'Do you have, or have you ever had, any of disease/complaints: other chronic respiratory disease other than asthma or chronic obstructive pulmonary disease?'.

\section{Cardiovascular disease and diabetes}

Participants were defined as having cardiovascular disease (CVD) if they answered yes to the following question: 'Do you have, or have you ever had, any of disease/complaints: heart attack/angina pectoris, congestive heart failure, stroke/brain haemorrhage or heart arrhythmia atrial fibrillation?'. Participants were defined as having diabetes if they responded affirmatively to the question, 'Has a physician ever diagnosed you with diabetes?'. Further, diabetes and cardiovascular disease were combined due to the close links between the two diseases. ${ }^{33}$

\section{Mental illness}

Participants were categorised as having had a mental illness if they responded affirmatively to the question, 'Have you ever had mental problems that you have sought help for?'.

\section{Covariates}

At baseline, information was obtained on sex, age and educational level. Age was treated as a continuous variable. Educational level was categorised as 'low' (primary school or lower secondary education), 'intermediate' (upper secondary and certificate) and 'high' (university or university college).

\section{Statistical analysis}

Descriptive statistics were presented as frequencies, with a proportion for categorical data and a mean with SD for continuous variables. Missing values for independent variables (diet, physical activity, BMI and smoking) and education were dealt with by a multiple imputation procedure which generated five imputed data sets. The percentage of missing values ranged from $0.5 \%$ for smoking to $17 \%$ for BMI. The imputation model included the covariates (age; sex), disease groups and dependent variables (sick leave and WAS at baseline) as predictors for independent variables to improve the imputation.

$\chi^{2}$ tests were used to assess whether there were statistically significant associations between the independent variables. $\chi^{2}$ tests were also used to explore whether sickness absence and work ability were associated.

To explore the association between lifestyle-related factors at baseline and duration of sick leave and level of WAS at follow-up, multinomial logistic regression analyses were performed. No sick leave and a WAS of 8 to 10 were used as reference categories, respectively. Separate models were used for each of the five lifestyle risk factors (diet, physical activity, BMI, smoking and lifestyle risk index score). All models were adjusted for age, sex, educational level and the dependent variable at baseline.

Similar analyses were performed to study the associations among participants in the disease groups. Due to lack of statistical power, sick leave and WAS were dichotomised as presence of (vs no) sick leave and low (vs good) work ability, respectively. Binary logistic regression analyses were performed to assess the association between lifestyle-related factors and, separately, presence of sick leave or a low WAS within each disease group. All analyses were adjusted for age, sex, educational level and the dependent variables at baseline. Results of multinomial and binary logistic regression analyses were presented as ORs with $95 \%$ CIs.

Population attributable fractions (PAF) were calculated to estimate the contribution of lifestyle risk factors to sick leave and low work ability. ${ }^{34}$

As a sensitivity analysis, the analyses were repeated for individuals with complete information on all the independent variables, dependent variables and employment status $(\mathrm{n}=5206)$.

In all analyses, statistical significance was defined as $p<0.05$. The statistical analyses were carried out using IBM SPSS Statistics for Windows, V.26. 


\section{Patient and public involvement}

The Telemark study includes user-representatives in the study planning, design and transfer of knowledge. Also an user-representative is member of the steering committee and has yielded valuable insights in development of questionnaires. All the results from the Telemark study is distributed to both study participants and the wider public (newspapers, radio, television and Internet).

\section{RESULTS}

The majority of the 6267 included participants was women $(57 \%)$, and the mean age was 39 years (SD 8.7) (table 1 ). In total, $15 \%$ had a mental illness, $11 \%$ a respiratory disease and $6 \%$ CVD or diabetes. Persons having one of the chronic diseases had a higher prevalence of sick leave and poor work ability (table 1 ).

Individual lifestyle risk factors were inter-related. Persons who reported an unhealthy diet were more likely to have low physical activity $\left(\chi^{2}=83.86, \mathrm{p}<0.05\right)$ than persons with a healthy diet. Further, persons who did not engage in physical activity were more likely to smoke $\left(\chi^{2}=70.91, p<0.05\right)$ than persons who engaged in physical activity.

Persons who reported sick leave were more likely to have poor work ability than persons having a good work ability $\left(\chi^{2}=463, \mathrm{p}<0.05\right)$.

\section{Unhealthy lifestyle and sick leave: general population}

In the general population, overweight and obesity and former and current smoking at baseline were associated with duration of sick leave at follow-up, after adjusting for demographics and sick leave at baseline (table 2). These associations were strongest for long-term sick leave. Persons with obesity were 1.64 (95\% CI: 1.32 to 2.05 ) times more likely to have long-term sick leave than individuals with a healthy body weight. In addition, former and current smoking was statistically significantly associated with both moderate sick leave and long-term sick leave. Further, exposure to multiple unhealthy risk factors was associated with a higher likelihood of sick leave. A higher score on the unhealthy lifestyle risk score was associated with a higher risk of long-term sickness absence compared with individuals with a low lifestyle risk score. Unhealthy diet and low physical activity were not associated with a higher risk of sick leave.

As regards to individual lifestyle risk factors, the highest PAF for long-term sick leave was found in relation to current smoking $(11 \%)$. The other PAFs were $8 \%$ for obesity, $2 \%$ for unhealthy diet and $0.2 \%$ for low physical activity. The combined PAF for long-term sick leave showed that $20 \%$ of long-term sick leave could be attributed to unhealthy lifestyle risk factors.

\section{Unhealthy lifestyle and reduced work ability: general population}

Persons with an unhealthy diet, who do not achieve the recommended level of physical activity, or who smoke or smoked were more likely to have a low WAS than those who have a healthy diet, achieve physical activity recommendations or have never smoked. Further, a statistically significant association was found between a high or very high lifestyle risk score and moderate or poor WAS (table 3).

In the case of poor WAS, current smoking yielded the highest PAF (12\%). The PAFs for unhealthy diet and obesity, and low physical activity were $4 \%, 4 \%$ and $3 \%$, respectively. The combined PAF showed that $21 \%$ of poor WAS could be attributed to unhealthy lifestyle risk factors.

\section{Unhealthy lifestyle, sick leave and reduced work ability within disease groups}

As regards to persons with specific diseases, those who smoke or persons being overweight or obese, and persons with a higher lifestyle risk index were more likely to have one or more days off work due to sick leave. However, only a few of these associations were statistically significant (table 4).

Among workers with specific diseases, the associations between moderate MVPA, current smoking and low WAS had ORs above 1. However, only the association between former smoking and low WAS was statistically significant among persons with a mental illness ( $\mathrm{n}=322$ with low WAS) (table 5).

A sensitivity analysis on the complete data set without any missing values $(n=5206)$ yielded similar results to the analyses with imputed data (online supplemental file).

\section{DISCUSSION}

This longitudinal study of a general working population found associations between unhealthy lifestyle factors on one hand and sick leave and reduced work ability on the other hand. Unhealthy diet, moderate and low physical activity, and current smoking were consistently associated with low work ability. Sick leave, and long-term sick leave in particular, was associated with smoking and BMI. Exposure to multiple unhealthy lifestyle factors increased the risk of sick leave and poor work ability. The combined PAFs for long-term sick leave (20\%) and poor WAS (21\%) indicate that an unhealthy lifestyle contributes substantially to sick leave and low work ability. Moreover, unhealthy lifestyle factors-in particular overweight, smoking and exposure to multiple lifestyle risk factors-were found to be associated with sick leave in groups with a specific disease. However, no consistent associations were found between lifestyle risk factors and low WAS in the specific disease groups.

We have previously reported an additive association between multiple lifestyle risk factors and low work ability in a cross-sectional study of a general working population in Norway. ${ }^{21}$ A small Polish cross-sectional study indicated a similar additive association between unhealthy lifestyle risk factors and low work ability. ${ }^{35}$ To the best of our knowledge, no other studies have explored the association between a multiple lifestyle risk index and sick leave 
Table 1 Baseline characteristics of the total study population $(n=6267)$ and workers with respiratory disease $(n=688), C V D$ or diabetes $(n=348)$ and mental illness $(n=948)$

\begin{tabular}{|c|c|c|c|c|}
\hline & $\begin{array}{l}\text { Total } \\
\mathrm{n}=6267\end{array}$ & $\begin{array}{l}\text { Respiratory } \\
\text { disease } \\
n=688\end{array}$ & $\begin{array}{l}\text { CVD or diabetes } \\
\mathrm{n}=348\end{array}$ & $\begin{array}{l}\text { Mental illness } \\
\mathrm{n}=948\end{array}$ \\
\hline Age in years $(m, S D)$ & 39 (SD 8.7) & 38 (SD 8.8) & 42 (SD 7.9) & 39 (SD 8.7) \\
\hline \multicolumn{5}{|l|}{ Sex } \\
\hline Female & $3583(57)$ & $412(60)$ & $174(50)$ & $671(71)$ \\
\hline Male & $2684(43)$ & $276(40)$ & $174(50)$ & $277(29)$ \\
\hline \multicolumn{5}{|l|}{ Education } \\
\hline Low & $683(11)$ & $66(10)$ & $46(13)$ & $95(10)$ \\
\hline Intermediate & $2244(36)$ & $244(36)$ & $150(43)$ & $312(33)$ \\
\hline High & $3340(53)$ & $378(54)$ & $152(44)$ & $541(57)$ \\
\hline \multicolumn{5}{|l|}{ Diet } \\
\hline Healthy & $3708(59)$ & $395(57)$ & $205(59)$ & $525(55)$ \\
\hline Average & $2128(34)$ & $254(37)$ & $122(35)$ & $341(36)$ \\
\hline Unhealthy & $431(7)$ & $39(6)$ & $21(6)$ & $82(9)$ \\
\hline \multicolumn{5}{|l|}{ Physical activity } \\
\hline High MVPA & $3358(54)$ & $387(56)$ & $174(50)$ & $515(54)$ \\
\hline Moderate MVPA & $1709(27)$ & $177(26)$ & $102(29)$ & $249(26)$ \\
\hline Low MVPA & $1200(19)$ & $124(18)$ & $72(21)$ & $184(20)$ \\
\hline \multicolumn{5}{|l|}{ Body mass index } \\
\hline Under and normal weight & $3086(49)$ & $289(42)$ & $127(36)$ & $492(52)$ \\
\hline Overweight & 2294 (37) & $268(39)$ & $134(39)$ & $328(34)$ \\
\hline Obese & $887(14)$ & $131(19)$ & $87(25)$ & $128(14)$ \\
\hline \multicolumn{5}{|l|}{ Smoking } \\
\hline Never & $3535(57)$ & $389(57)$ & $153(44)$ & $427(45)$ \\
\hline Past & $1453(23)$ & $167(24)$ & $105(30)$ & $261(28)$ \\
\hline Current & $1279(20)$ & $132(19)$ & $90(26)$ & $260(27)$ \\
\hline \multicolumn{5}{|l|}{ Lifestyle risk index } \\
\hline Low risk score $(0-0.5)$ & 2001 (32) & $213(31)$ & $68(20)$ & $246(26)$ \\
\hline Medium risk score (1-1.5) & $2739(44)$ & $297(43)$ & $166(47)$ & $447(47)$ \\
\hline High risk score (2-2.5) & $1268(20)$ & $146(21)$ & $87(25)$ & $206(22)$ \\
\hline Very high risk score (3-4) & $259(4)$ & $32(5)$ & $27(8)$ & $49(5)$ \\
\hline \multicolumn{5}{|l|}{ Sick leave duration (follow-up) } \\
\hline No sick leave (0 days) & $4387(70)$ & $419(61)$ & $219(63)$ & $559(59)$ \\
\hline Short-term sick leave (1-14 days) & $960(15)$ & $118(17)$ & $51(15)$ & $165(17)$ \\
\hline Long-term sick leave (15+days) & $920(15)$ & $151(22)$ & $78(22)$ & $224(24)$ \\
\hline \multicolumn{5}{|l|}{ Work ability score (follow-up) } \\
\hline Good (8-10) & $5362(85)$ & $559(81)$ & $255(73)$ & $716(75)$ \\
\hline Moderate (6-7) & $554(9)$ & $76(11)$ & $52(15)$ & $131(14)$ \\
\hline Poor (0-5) & 351 (6) & $53(8)$ & $41(12)$ & $101(11)$ \\
\hline
\end{tabular}

Numbers are frequencies and proportions unless otherwise specified. Missing: smoking (0.5\%), education (2\%), diet (3\%), physical activity (3\%), BMI (17\%).

CVD, cardiovascular disease; MVPA, moderate to vigorous leisure-time physical activity.

or work ability over time. Data from four European cohort studies indicate that co-occurrence of lifestyle risk factors such as physical inactivity, high BMI and smoking leads to reduced life-years lived in good health. ${ }^{20}$ Although limited literature is available on the effectiveness of health promotion activities with regard to work ability 
Table 2 Associations between lifestyle-related factors at baseline and short-term and long-term sick leave in the general population $(n=6267)$

\begin{tabular}{|c|c|c|}
\hline & $\begin{array}{l}\text { Short-term sick } \\
\text { leave* }^{*} \\
1-14 \text { days }(n=960) \\
\text { OR }(95 \% \text { Cl) }\end{array}$ & $\begin{array}{l}\text { Long-term sick } \\
\text { leave* } \\
15+\text { days }(n=920) \\
\text { OR }(95 \% \mathrm{Cl})\end{array}$ \\
\hline \multicolumn{3}{|l|}{ Diet } \\
\hline Average & 1.05 (0.90 to 1.23$)$ & 1.00 (0.85 to 1.18$)$ \\
\hline Unhealthy & 1.09 (0.82 to 1.46$)$ & 1.32 (0.99 to 1.74$)$ \\
\hline \multicolumn{3}{|l|}{ Physical activity } \\
\hline Moderate MVPA & $1.02(0.86$ to 1.21$)$ & 1.15 (0.97 to 1.37$)$ \\
\hline Low MVPA & 1.14 (0.94 to 1.38$)$ & 1.01 (0.82 to 1.24$)$ \\
\hline \multicolumn{3}{|l|}{ Body mass index } \\
\hline Overweight & 1.24 (1.04 to 1.47$)$ & 1.27 (1.06 to 1.52$)$ \\
\hline Obese & 1.25 (0.99 to 1.56$)$ & 1.64 (1.32 to 2.05$)$ \\
\hline \multicolumn{3}{|l|}{ Smoking } \\
\hline Former & 1.31 (1.10 to 1.57$)$ & 1.28 (1.06 to 1.54$)$ \\
\hline Current & $1.50(1.25$ to 1.80$)$ & $1.62(1.35$ to 1.96$)$ \\
\hline \multicolumn{3}{|l|}{ Lifestyle risk index } \\
\hline Medium risk score & 1.09 (0.91 to 1.30$)$ & 1.31 (1.08 to 1.59$)$ \\
\hline High risk score & $1.26(1.02$ to 1.56$)$ & 1.59 (1.28 to 1.99$)$ \\
\hline Very high risk score & 1.89 (1.32 to 2.71$)$ & 1.89 (1.27 to 2.81$)$ \\
\hline
\end{tabular}

Adjusted for age, sex, education and sick leave at baseline. *Reference category is 0 sick leave days.

MVPA, moderate to vigorous leisure-time physical activity.

and sick leave ${ }^{36}$ our study provides support for focussing on multiple lifestyle risk factors as a means of reducing sick leave and enhancing work ability. Our finding that persons with multiple lifestyle risk factors are more likely to have a lower work ability and higher sickness absence may imply that an unhealthy lifestyle will incur costs for the employer. A recent Finnish cohort study following sick leave over a 14-year long period (2002-2016) found that individuals having $\geq 3$ lifestyle risk factors (high alcohol consumption, low fruit or vegetable intake, being physical inactive, currently smoker or having sleep disruption) resulted in an additional expense for the employer of $3266 €$, compared with those with no risk factors. ${ }^{37}$

In this study, we found that some $20 \%$ of long-term sick leave could be attributed to unhealthy lifestyle factors. This is consistent with Virtanen et al (2018), who found that $15 \%$ to $30 \%$ of sick leave could be attributed to lifestyle risk factors. ${ }^{38}$ Our study also shows that obesity and smoking are associated with sick leave, and long-term sick leave particularly. This is in line with the results of the Virtanen study. ${ }^{14}$ Moreover, recent systematic reviews have found BMI and smoking to be associated with sick leave. ${ }^{71213}$ Amiri have shown that workers who are overweight or obese have a 1.2 to 1.3 times higher risk of sick leave than workers with a healthy body weight. ${ }^{7}$ Troelstra et al have reported that smoking is associated with a $31 \%$ increase in risk of sick leave. ${ }^{13}$ Obesity and smoking are risk
Table 3 Associations between unhealthy lifestyle-related factors at baseline and the level of WAS at follow-up in the general population $(n=6267)$

\begin{tabular}{|c|c|c|}
\hline & $\begin{array}{l}\text { Moderate WAS } \\
(6-7)^{*} \\
(n=554) \\
\text { OR }(95 \% \mathrm{CI})\end{array}$ & $\begin{array}{l}\text { Poor WAS }(0-5)^{*} \\
(n=351) \\
\text { OR }(95 \% \mathrm{Cl})\end{array}$ \\
\hline \multicolumn{3}{|l|}{ Diet } \\
\hline Average & $1.15(0.94$ to 1.41$)$ & $1.18(0.91$ to 1.54$)$ \\
\hline Unhealthy & 1.42 (1.01 to 2.00$)$ & 1.57 (1.01 to 2.43$)$ \\
\hline \multicolumn{3}{|l|}{ Physical activity } \\
\hline Moderate MVPA & 1.35 (1.09 to 1.69$)$ & 1.29 (0.98 to 1.71$)$ \\
\hline Low MVPA & 1.41 (1.11 to 1.79$)$ & $1.17(0.85$ to 1.61$)$ \\
\hline \multicolumn{3}{|l|}{ Body mass index } \\
\hline Overweight & $1.16(0.93$ to 1.44$)$ & 1.17 (0.86 to 1.58$)$ \\
\hline Obese & $1.12(0.83$ to 1.50$)$ & $1.30(0.92$ to 1.84$)$ \\
\hline \multicolumn{3}{|l|}{ Smoking } \\
\hline Former & $1.03(0.82$ to 1.30$)$ & $1.36(1.01$ to 1.83$)$ \\
\hline Current & 1.36 (1.09 to 1.71$)$ & 1.67 (1.24 to 2.25$)$ \\
\hline \multicolumn{3}{|l|}{ Lifestyle risk index } \\
\hline $\begin{array}{l}\text { Medium risk } \\
\text { score }\end{array}$ & $1.18(0.92$ to 1.50$)$ & 1.32 (0.94 to 1.85$)$ \\
\hline High risk score & $1.52(1.16$ to 1.99$)$ & 1.58 (1.11 to 2.62 ) \\
\hline $\begin{array}{l}\text { Very high risk } \\
\text { score }\end{array}$ & $1.93(1.25$ to 2.98$)$ & 2.54 (1.49 to 4.31$)$ \\
\hline
\end{tabular}

Adjusted for age, sex, education and WAS at baseline.

*Reference category is 8-10 WAS.

MVPA, moderate to vigorous leisure-time physical activity; WAS, work ability score.

factors with respect to several diseases, including mental illness and cardiovascular disease, which are themselves risk factors for sick leave. ${ }^{712} 13$ Moreover, smokers are more susceptible to respiratory problems and a reduced immune system, which could increase the risk of shortterm sick leave due to, for example, the common cold/ influenza. ${ }^{13}$ Importantly, encouraging results have been reported regarding workplace intervention of smoke cessation. $^{13}$

Our study could not confirm associations between an unhealthy diet or insufficient physical activity and sick leave. In a systematic review, Kerner et $a l^{11}$ have shown that 11 out of 15 included studies reported an association between lower leisure-time physical activity and sick leave. It is important to note, however, that comparison of results in this area is challenging because different studies employ different measures of leisure-time physical activity and different cut-offs for sick leave days.

Concerning work ability, we did find an association between unhealthy diet, moderate and low MVPA and former and current smoking at baseline and low work ability after 5 years. Unfavourable baseline levels of physical activity were also associated with moderate and poor WAS at follow-up. This is consistent with a scoping review 
Table 4 Associations between unhealthy lifestyle-related factors at baseline and the presence of sick leave at followup among workers with respiratory diseases $(n=688)$, cardiovascular diseases or diabetes $(n=348)$ or mental illness $(n=948)$

\begin{tabular}{|c|c|c|c|}
\hline & \multicolumn{3}{|c|}{ Sick leave (yes vs no) } \\
\hline & $\begin{array}{l}\text { Respiratory } \\
\text { disease } \\
n=269 / 688 \\
\text { OR }(95 \% \mathrm{Cl})\end{array}$ & $\begin{array}{l}\text { CVD or } \\
\text { diabetes } \\
n=129 / 438 \\
\text { OR }(95 \% \mathrm{Cl})\end{array}$ & $\begin{array}{l}\text { Mental } \\
\text { illness } \\
\mathrm{n}=389 / 948 \\
\text { OR }(95 \% \mathrm{Cl})\end{array}$ \\
\hline \multicolumn{4}{|l|}{ Diet } \\
\hline Average & $\begin{array}{l}1.04(0.74 \text { to } \\
1.48)\end{array}$ & $\begin{array}{l}0.87(0.52 \text { to } \\
1.46)\end{array}$ & $\begin{array}{l}1.10(0.82 \text { to } \\
1.47)\end{array}$ \\
\hline Unhealthy & $\begin{array}{l}1.16(0.57 \text { to } \\
2.34)\end{array}$ & $\begin{array}{l}1.30(0.49 \text { to } \\
3.41)\end{array}$ & $\begin{array}{l}1.28(0.78 \text { to } \\
2.09)\end{array}$ \\
\hline \multicolumn{4}{|l|}{ Physical activity } \\
\hline $\begin{array}{l}\text { Moderate } \\
\text { MVPA }\end{array}$ & $\begin{array}{l}1.17 \text { (0.80 to } \\
1.71)\end{array}$ & $\begin{array}{l}0.89(0.51 \text { to } \\
1.53)\end{array}$ & $\begin{array}{l}0.76(0.55 \text { to } \\
1.06)\end{array}$ \\
\hline Low MVPA & $\begin{array}{l}0.74(0.47 \text { to } \\
1.17)\end{array}$ & $\begin{array}{l}1.06(0.58 \text { to } \\
1.94)\end{array}$ & $\begin{array}{l}0.99 \text { (0.69 to } \\
1.42)\end{array}$ \\
\hline \multicolumn{4}{|c|}{ Body mass index } \\
\hline Overweight & $\begin{array}{l}1.31(0.87 \text { to } \\
1.95)\end{array}$ & $\begin{array}{l}0.99(0.52 \text { to } \\
1.89)\end{array}$ & $\begin{array}{l}1.45 \text { (0.98 to } \\
2.16)\end{array}$ \\
\hline Obese & $\begin{array}{l}1.45(0.87 \text { to } \\
2.43)\end{array}$ & $\begin{array}{l}1.25(0.60 \text { to } \\
2.60)\end{array}$ & $\begin{array}{l}1.34(0.81 \text { to } \\
2.21)\end{array}$ \\
\hline \multicolumn{4}{|l|}{ Smoking } \\
\hline Former & $\begin{array}{l}1.33(0.89 \text { to } \\
1.98)\end{array}$ & $\begin{array}{l}1.58(0.91 \text { to } \\
2.75)\end{array}$ & $\begin{array}{l}1.10(0.79 \text { to } \\
1.53)\end{array}$ \\
\hline Current & $\begin{array}{l}1.31(0.85 \text { to } \\
2.00)\end{array}$ & $\begin{array}{l}1.81(1.01 \text { to } \\
3.25)\end{array}$ & $\begin{array}{l}1.42(1.02 \text { to } \\
1.98)\end{array}$ \\
\hline \multicolumn{4}{|c|}{ Lifestyle risk index } \\
\hline $\begin{array}{l}\text { Medium risk } \\
\text { score }\end{array}$ & $\begin{array}{l}1.51(1.01 \text { to } \\
2.24)\end{array}$ & $\begin{array}{l}1.24(0.63 \text { to } \\
2.45)\end{array}$ & $\begin{array}{l}1.40(0.99 \text { to } \\
1.99)\end{array}$ \\
\hline High risk score & $\begin{array}{l}1.24 \text { (0.77 to } \\
1.99)\end{array}$ & $\begin{array}{l}1.48 \text { (0.67 to } \\
3.31)\end{array}$ & $\begin{array}{l}1.46 \text { (0.95 to } \\
2.24)\end{array}$ \\
\hline $\begin{array}{l}\text { Very high risk } \\
\text { score }\end{array}$ & $\begin{array}{l}1.25 \text { (0.54 to } \\
2.91)\end{array}$ & $\begin{array}{l}1.52 \text { (0.56 to } \\
4.18)\end{array}$ & $\begin{array}{l}1.42 \text { ( } 0.71 \text { to } \\
2.84)\end{array}$ \\
\hline
\end{tabular}

Adjusted for age, sex, education and sick leave at baseline. No sick leave is the reference category.

CVD, cardiovascular disease; MVPA, moderate to vigorous leisure-time physical activity.

focussing on worksite physical activity interventions. ${ }^{18}$ Further, a recent randomised controlled trial among workers at the Volkswagen factory in Germany found that participants with metabolic syndrome benefited from activity-monitored and supported exercise (face-toface meetings and a smartphone application). Not only did the participants improve on metabolic syndrome parameters, but the intervention group also increased its work ability compared with the control group after the 6 month intervention. ${ }^{39}$ Although the intervention period was limited, the results are promising in terms of reducing disease risk and improving work ability. Many workers spend most of their working lives in sitting or
Table 5 Associations between unhealthy lifestyle-related factors at baseline and the presence of a low WAS at follow-up among workers with respiratory diseases $(n=688)$, cardiovascular diseases or diabetes $(n=348)$ or mental illness $(\mathrm{n}=948)$

\begin{tabular}{|c|c|c|c|}
\hline & \multicolumn{3}{|c|}{ WAS $(0-7$ vs $\geq 8)$} \\
\hline & $\begin{array}{l}\text { Respiratory } \\
\text { disease } \\
n=129 / 688 \\
\text { OR }(95 \% \mathrm{Cl})\end{array}$ & $\begin{array}{l}\text { CVD or } \\
\text { diabetes } \\
n=93 / 348 \\
\text { OR }(95 \% \text { Cl) }\end{array}$ & $\begin{array}{l}\text { Mental } \\
\text { illness } \\
\mathrm{n}=332 / 948 \\
\text { OR }(95 \% \mathrm{Cl})\end{array}$ \\
\hline \multicolumn{4}{|l|}{ Diet } \\
\hline Average & $\begin{array}{l}0.91(0.57 \text { to } \\
1.44)\end{array}$ & $\begin{array}{l}1.01(0.56 \text { to } \\
1.81)\end{array}$ & $\begin{array}{l}1.06(0.74 \text { to } \\
1.51)\end{array}$ \\
\hline Unhealthy & $\begin{array}{l}0.85 \text { (0.32 to } \\
2.27)\end{array}$ & $\begin{array}{l}0.67(0.19 \text { to } \\
2.40)\end{array}$ & $\begin{array}{l}0.96(0.52 \text { to } \\
1.76)\end{array}$ \\
\hline \multicolumn{4}{|l|}{ Physical activity } \\
\hline $\begin{array}{l}\text { Moderate } \\
\text { MVPA }\end{array}$ & $\begin{array}{l}1.21(0.73 \text { to } \\
2.01)\end{array}$ & $\begin{array}{l}1.11(0.57 \text { to } \\
2.15)\end{array}$ & $\begin{array}{l}1.35 \text { (0.90 to } \\
2.03)\end{array}$ \\
\hline Low MVPA & $\begin{array}{l}0.87(0.47 \text { to } \\
1.51)\end{array}$ & $\begin{array}{l}0.97(0.47 \text { to } \\
2.03)\end{array}$ & $\begin{array}{l}1.15(0.73 \text { to } \\
1.80)\end{array}$ \\
\hline \multicolumn{4}{|c|}{ Body mass index } \\
\hline Overweight & $\begin{array}{l}1.29(0.78 \text { to } \\
2.16)\end{array}$ & $\begin{array}{l}0.93(0.47 \text { to } \\
1.82)\end{array}$ & $\begin{array}{l}0.95(0.64 \text { to } \\
1.41)\end{array}$ \\
\hline Obese & $\begin{array}{l}1.20(0.60 \text { to } \\
2.40)\end{array}$ & $\begin{array}{l}1.00(0.47 \text { to } \\
2.14)\end{array}$ & $\begin{array}{l}0.97(0.50 \text { to } \\
1.88)\end{array}$ \\
\hline \multicolumn{4}{|l|}{ Smoking } \\
\hline Former & $\begin{array}{l}1.04(0.62 \text { to } \\
1.74)\end{array}$ & $\begin{array}{l}1.10(0.57 \text { to } \\
2.11)\end{array}$ & $\begin{array}{l}0.57(0.37 \text { to } \\
0.88)\end{array}$ \\
\hline Current & $\begin{array}{l}1.17(0.67 \text { to } \\
2.05)\end{array}$ & $\begin{array}{l}1.08(0.55 \text { to } \\
2.15)\end{array}$ & $\begin{array}{l}0.95(0.64 \text { to } \\
1.41)\end{array}$ \\
\hline \multicolumn{4}{|c|}{ Lifestyle risk index } \\
\hline $\begin{array}{l}\text { Medium risk } \\
\text { score }\end{array}$ & $\begin{array}{l}1.21(0.67 \text { to } \\
2.18)\end{array}$ & $\begin{array}{l}1.49(0.65 \text { to } \\
3.41)\end{array}$ & $\begin{array}{l}0.82(0.54 \text { to } \\
1.25)\end{array}$ \\
\hline $\begin{array}{l}\text { High risk } \\
\text { score }\end{array}$ & $\begin{array}{l}1.03(0.53 \text { to } \\
2.00)\end{array}$ & $\begin{array}{l}1.08(0.42 \text { to } \\
2.80)\end{array}$ & $\begin{array}{l}0.87(0.53 \text { to } \\
1.45)\end{array}$ \\
\hline $\begin{array}{l}\text { Very high } \\
\text { risk score }\end{array}$ & $\begin{array}{l}0.72 \text { (0.22 to } \\
2.35)\end{array}$ & $\begin{array}{l}0.87(0.25 \text { to } \\
3.03)\end{array}$ & $\begin{array}{l}1.41(0.67 \text { to } \\
2.96)\end{array}$ \\
\hline
\end{tabular}

Adjusted for age, sex, education and WAS at baseline. WAS of $8-10$ is the reference.

CVD, cardiovascular disease; MVPA, moderate to vigorous leisuretime physical activity; WAS, work ability score.

other sedentary positions. ${ }^{40}$ Increasing efforts to enhance leisure-time physical activity therefore seems warranted.

The PAFs of $20 \%$ and $21 \%$ observed in our study, indicate that interventions focussed on lifestyle risk factors could in theory work ability and reduce sickness absence. However, further evidence is needed on healthpromotion programmes to prevent low work ability. ${ }^{41}$ It could be hypothesised that healthy behaviours would improve physical and mental health ${ }^{42}$ and decrease BMI, and thereby increase work ability and reduce sick leave in a general working population.

To the best of our knowledge, few studies have explored these relationships among persons with chronic diseases. 
Although not statistically significant, our results show ORs above 1 for the associations between obesity and smoking and sick leave within the specific disease groups. A Dutch cross-sectional study of 8364 healthcare employees ${ }^{22}$ found statistically significant associations between smoking, obesity and low work ability among persons with respiratory diseases. The same study also found smoking to be associated with sick leave among persons with a mental illness. ${ }^{22}$ Partly due to low numbers in each disease category and a resulting lack of statistical power, our hypothesis regarding an increased risk of sick leave and work ability among persons with common chronic diseases and an unhealthy lifestyle was not confirmed. Although few statistically significant associations were found in the specific disease groups, our results did show ORs above 1 for the associations between overweight, obesity, smoking, the lifestyle risk index and sick leave in these groups. As regards the chronic disease groups, we cannot exclude a healthy worker effect entailing exclusion of workers with more severe chronic diseases and unhealthy lifestyles from the workforce.

\section{Strengths and limitations}

The 5-year follow-up period is a strength of this study. Most available studies have a cross-sectional design or a shorter follow-up period. Another strength is that this study was performed on the general working population, and thus included participants both from a broad spectre of adults with different sociodemographic backgrounds. Further, this study used validated questions to assess the independent variables. These questions have previously been used in the HUNT1 and HUNT 3 studies. ${ }^{28}{ }^{30}$ This allows comparison in the Norwegian context.

An important limitations of the study is the low number of persons in each disease group. The lack of statistical power makes it difficult to draw conclusions regarding these groups. Furthermore, due to the low response (33\%) generalisation is challenging. Nevertheless, analyses of non-responders indicate comparable results to those of responders. ${ }^{43}$ Due to the high number of missing values, missing values were imputed. As mentioned, the results are comparable with complete case analyses. However, we cannot rule out the possibility of selection bias in this study. Moreover, this study relies on self-reporting by participants. This may entail underestimation or overestimation of unhealthy behaviours. Nevertheless, the questions on both diet and physical activity have previously proven to be valid and reliable measures when compared with objective measures. ${ }^{30} 44$

Given that this study only included persons engaged in paid work during the past 12 months or below the age of 50 years at baseline, the results cannot be generalised to persons who are not engaged in paid work, or to older age groups. Prior research indicates that employment status and high age could both be indicators of poor work ability. ${ }^{6}$ However, other factors which may be important were not available in our study, such as family income, productivity or reasons for sickness absence. Moreover, we do not have detailed information on remission or severity of disease which might have altered our results.

Due to the different follow-up periods reported in the different longitudinal studies, cross-study comparison is difficult. A 5-year follow-up period may also be too short to detect changes in work ability and sick leave due to lifestyle changes. As a result, our findings could underestimate the relationship between lifestyle risk factors and work ability and sick leave.

\section{CONCLUSION}

In this longitudinal study, statistically significant associations were found between lifestyle risk factors and long-term sick leave and poor work ability. Further, exposure to multiple lifestyle risk factors was associated with subsequent more sick leave and reduced work ability. The findings related to specific disease groups were less consistent. However, based on the results of our work, we would encourage employers to facilitate-in addition to a healthy work environment-healthy lifestyles. The results indicate that studies assessing lifestyle interventions are needed to investigate the effect on sick leave and work ability.

Acknowledgements The authors wish to thank the Telemark study research group for data collection, and Martin Veel Svendsen for preparation of the data set. The authors are grateful to Professor Johny Kongerud for his contribution to the design of the main study, and to Ragnhild Sørum Falk for her assistance with the statistical analysis.

Contributors AKMF was involved in conception, design and data collection. MMDB, IMO, AKMF, SJWR and AB were involved in the selection of research questions. MMDB was responsible for the statistical analyses. MMDB, IM0, AKMF, SJWR and $A B$ were involved in the interpretation of the results. MMDB drafted the manuscript with the assistance of SJWR. MMDB, IMO, AKMF, SJWR and AB revised the manuscript critically and approved the final manuscript.

Funding The work was supported by the University of South-Eastern Norway and Telemark Hospital.

Competing interests None declared.

Patient consent for publication Not required.

Ethics approval The study was conducted in accordance with the guidelines laid down in the Declaration of Helsinki, and were approved by the Regional Committee for Ethics in Medical Research and the Norwegian Data Protection Authority (REC 2012/1665).

Provenance and peer review Not commissioned; externally peer reviewed.

Data availability statement Data are available upon reasonable request. The data sets generated and/or analysed during the current study are not publicly available due to individual privacy regulations. However, data may be shared with researchers who meet the criteria for access to confidential data upon request to the head of the Telemark study steering committee.

Supplemental material This content has been supplied by the author(s). It has not been vetted by BMJ Publishing Group Limited (BMJ) and may not have been peer-reviewed. Any opinions or recommendations discussed are solely those of the author(s) and are not endorsed by BMJ. BMJ disclaims all liability and responsibility arising from any reliance placed on the content. Where the content includes any translated material, BMJ does not warrant the accuracy and reliability of the translations (including but not limited to local regulations, clinical guidelines, terminology, drug names and drug dosages), and is not responsible for any error and/or omissions arising from translation and adaptation or otherwise.

Open access This is an open access article distributed in accordance with the Creative Commons Attribution Non Commercial (CC BY-NC 4.0) license, which permits others to distribute, remix, adapt, build upon this work non-commercially, 
and license their derivative works on different terms, provided the original work is properly cited, appropriate credit is given, any changes made indicated, and the use is non-commercial. See: http://creativecommons.org/licenses/by-nc/4.0/.

\section{ORCID iDs}

Marit Müller De Bortoli http://orcid.org/0000-0002-3761-866X

Anne Kristin Moeller Fell http://orcid.org/0000-0002-3345-774X

Alex Burdorf http://orcid.org/0000-0003-3129-2862

\section{REFERENCES}

1 Astri Syse SN. Lower population growth in future 2018, 2020. Available: https://www.ssb.no/en/befolkning/artikler-ogpublikasjoner/lower-population-growth-in-future [Accessed 6 Jan 2020].

2 Olsen H. Norway 2013 : working better with age. Paris: OECD Publishing, 2013.

3 Markussen S, Røed K, Røgeberg OJ, et al. The anatomy of absenteeism. J Health Econ 2011;30:277-92.

4 Ilmarinen J, Tuomi K, Klockars M. Changes in the work ability of active employees over an 11-year period. Scand J Work Environ Health 1997;23:49-57.

5 Kinnunen U, Nätti J. Work ability score and future work ability as predictors of register-based disability pension and long-term sickness absence: a three-year follow-up study. Scand J Public Health 2018;46:321-30.

6 van den Berg TIJ, Elders LAM, de Zwart BCH, et al. The effects of work-related and individual factors on the work ability index: a systematic review. Occup Environ Med 2009;66:211-20.

7 Amiri S, Behnezhad S. Body mass index and risk of sick leave: a systematic review and meta-analysis. Clin Obes 2019;9:e12334.

8 Linaker CH, D'Angelo S, Syddall HE, et al. Body mass index (BMI) and work ability in older workers: results from the health and employment after fifty (Heaf) prospective cohort study. Int J Environ Res Public Health 2020;17 doi:10.3390/ijerph17051647

9 van Amelsvoort LGPM, Spigt MG, Swaen GMH, et al. Leisure time physical activity and sickness absenteeism; a prospective study. Occup Med 2006;56:210-2.

10 Lahti J, Laaksonen M, Lahelma E, et al. The impact of physical activity on sickness absence. Scand J Med Sci Sports 2010;20:191-9.

11 Kerner I, Rakovac M, Lazinica B. Leisure-time physical activity and absenteeism. Arh Hig Rada Toksikol 2017;68:159-70.

12 Weng SF, Ali S, Leonardi-Bee J. Smoking and absence from work: systematic review and meta-analysis of occupational studies. Addiction 2013;108:307-19.

13 Troelstra SA, Coenen P, Boot CR, et al. Smoking and sickness absence: a systematic review and meta-analysis. Scand J Work Environ Health 2020;46:5-18.

14 Virtanen M, Ervasti J, Head J, et al. Lifestyle factors and risk of sickness absence from work: a multicohort study. Lancet Public Health 2018;3:e545-54.

15 Tonnon SC, Robroek SRJ, van der Beek AJ, et al. Physical workload and obesity have a synergistic effect on work ability among construction workers. Int Arch Occup Environ Health 2019;92:855-64.

16 Nevanperä N, Ala-Mursula L, Seitsamo J, et al. Long-lasting obesity predicts poor work ability at midlife: a 15 -year follow-up of the Northern Finland 1966 birth cohort study. J Occup Environ Med 2015;57:1262-8.

17 Laitinen J, Näyhä S, Kujala V. Body mass index and weight change from adolescence into adulthood, waist-to-hip ratio and perceived work ability among young adults. Int J Obes 2005;29:697-702.

18 Lusa S, Punakallio A, Mänttäri S, et al. Interventions to promote work ability by increasing sedentary workers' physical activity at workplaces - A scoping review. Appl Ergon 2020;82:102962.

19 Meader N, King K, Moe-Byrne T, et al. A systematic review on the clustering and co-occurrence of multiple risk behaviours. BMC Public Health 2016;16:657.

20 Stenholm S, Head J, Kivimäki M, et al. Smoking, physical inactivity and obesity as predictors of healthy and disease-free life expectancy between ages 50 and 75: a multicohort study. Int $J$ Epidemiol 2016;45:1260-70.

21 Oellingrath IM, De Bortoli MM, Svendsen MV, et al. Lifestyle and work ability in a general working population in Norway: a crosssectional study. BMJ Open 2019;9:e026215.
22 van den Berg S, Burdorf A, Robroek SJW. Associations between common diseases and work ability and sick leave among health care workers. Int Arch Occup Environ Health 2017;90:1-9.

23 Sundstrup E, Jakobsen MD, Mortensen OS, et al. Joint association of multimorbidity and work ability with risk of long-term sickness absence: a prospective cohort study with register follow-up. Scand J Work Environ Health 2017;43:146-54.

24 Norwegian Labour and Welfare Administration A-ov. Sykefraværsstatistikk. Statistikk for 2. kvartal 2020 (Sickleave statistics. Statistics for second quarter. In Norwegian), 2020. Available: https://www.nav.no/no/nav-og-samfunn/statistikk/ sykefravar-statistikk/sykefravar [Accessed 9 Feb 2020].

25 Gould R, IImarinen J, Järvisalo J. Dimensions of work ability. results from the health 2000 survey Helsinki (Finland): Finnish centre for pensions. Occup Environ Health 2008;81:25-34.

26 Jaaskelainen A, Kausto J, Seitsamo J. Work ability index and perceived work ability as predictors of disability pension: a prospective study among Finnish municipal employees. Scand $J$ Work Environ Health 2016;42:490-9.

27 Krokstad S, Langhammer A, Hveem K. Cohort profile: the HUNT study, Norway. Int J Epidemiol 2013;42:968-77.

28 Mostad IL, Langaas M, Grill V. Central obesity is associated with lower intake of whole-grain bread and less frequent breakfast and lunch: results from the HUNT study, an adult all-population survey. Appl Physiol Nutr Metab 2014;39:819-28. doi:10.1139/apnm-20130356

29 Handeland K, Kjellevold M, Wik Markhus M. A diet score assessing Norwegian adolescents' adherence to dietary recommendationsdevelopment and test-retest reproducibility of the score. Nutrients2016;8.

30 Kurtze N, Rangul V, Hustvedt B-E, et al. Reliability and validity of self-reported physical activity in the nord-trøndelag health study: hunt 1. Scand J Public Health 2008;36:52-61. doi:10.1177/1403494807085373

31 Norwegian Directorate of Health (Helsedirektoratet). Anbefalinger Om kosthold, ernæring OG fysisk aktivitet (Norwegian guidelines on diet, nutrition and physical activity (in Norwegian), 2014.

32 World Health Organization. BMI classification 2004. Available: http:// apps.who.int/bmi/index.jsp? introPage=intro_3.html [Accessed 24 May 2017]

33 Leon BM, Maddox TM. Diabetes and cardiovascular disease: epidemiology, biological mechanisms, treatment recommendations and future research. World J Diabetes 2015;6:1246-58.

34 Rothman KJ, Greenland S, Lash TL. Modern epidemiology. 3rd edn. Philadelphia: Lippincott Williams \& Wilkins, 2008.

35 Kaleta D, Makowiec-Dąbrowska T, Jegier A. Lifestyle index and work ability. Int J Occup Med Environ Health 2006;170.

36 Rongen A, Robroek SJW, van Lenthe FJ. Workplace health promotion: a meta-analysis of effectiveness. Am J Prev Med 2013:44:406-15

37 Kanerva N, Pietiläinen O, Lallukka T. Unhealthy lifestyle and sleep problems as risk factors for increased direct employers' cost of short-term sickness absence. Scand J Work Environ Health 2018;44:192-201.

38 Burdorf A, Robroek S. Does lifestyle matter for sickness absence? Lancet Public Health 2018;3:e513-4. doi:10.1016/S24682667(18)30211-1

39 Haufe S, Kerling A, Protte G. Telemonitoring-supported exercise training, metabolic syndrome severity, and work ability in company employees: a randomised controlled trial. Lancet Public health 2019:4:e343-52.

40 Thorp AA, Healy GN, Winkler E, et al. Prolonged sedentary time and physical activity in workplace and non-work contexts: a cross-sectional study of office, customer service and call centre employees. Int J Behav Nutr Phys Act 2012;9:128. doi:10.1186/14795868-9-128

41 Oakman J, Neupane S, Proper KI. Workplace interventions to improve work ability: a systematic review and meta-analysis of their effectiveness. Scand J Work Environ Health 2018;44:134-46.

42 Blank L, Grimsley M, Goyder E. Community-based lifestyle interventions: changing behaviour and improving health. J Public Health 2007;29:236-45.

43 Abrahamsen R, Svendsen MV, Henneberger PK. Non-response in a cross-sectional study of respiratory health in Norway. BMJ Open 2016;6.

44 Mosdol A. Dietary assessment - the weakest link?: a dissertation exploring the limitations to questionnaire based methods of dietary assessment. [Ph.D]. University of Oslo 2004 